\title{
Correction to: Factors influencing the occurrence of fall armyworm parasitoids in Zambia
}

\author{
Léna Durocher-Granger ${ }^{1,2}$ (D) Tibonge Mfune ${ }^{3} \cdot$ Monde Musesha $^{3} \cdot$ Alyssa Lowry $^{4} \cdot$ Kathryn Reynolds $^{5}$. \\ Alan Buddie ${ }^{4}$ - Giovanni Cafà ${ }^{4}$. Lisa Offord ${ }^{4}$. Gilson Chipabika ${ }^{3} \cdot$ Marcel Dicke $^{1} \cdot$ Marc Kenis $^{6}$
}

Published online: 22 September 2021

○) Springer-Verlag GmbH Germany, part of Springer Nature 2021

Correction to: Journal of Pest Science (2021) 94:1133-1146
https://doi.org/10.1007/s10340-020-01320-9

Following publication of the original article, the authors identified an error in Fig. 6.
The correct Fig. 6 and its caption is given below. The Original article has been revised.

The original article can be found online at https://doi.org/10.1007/ s10340-020-01320-9.

Léna Durocher-Granger

1.durocher-granger@ cabi.org

1 Laboratory of Entomology, Wageningen University and Research, Wageningen, The Netherlands

2 CABI, Leusderend 32, 3832 RC Leusden, The Netherlands

3 Zambia Agriculture Research Institute, Mount Makulu Research Station, Chilanga, Zambia

4 CABI, Bakeham Lane, Egham TW20 9TY, UK

5 CABI, Nosworthy Way, Wallingford OX10 8DE, UK

6 CABI, 1 Rue des Grillons, 2800 Delémont, Switzerland 
0.6

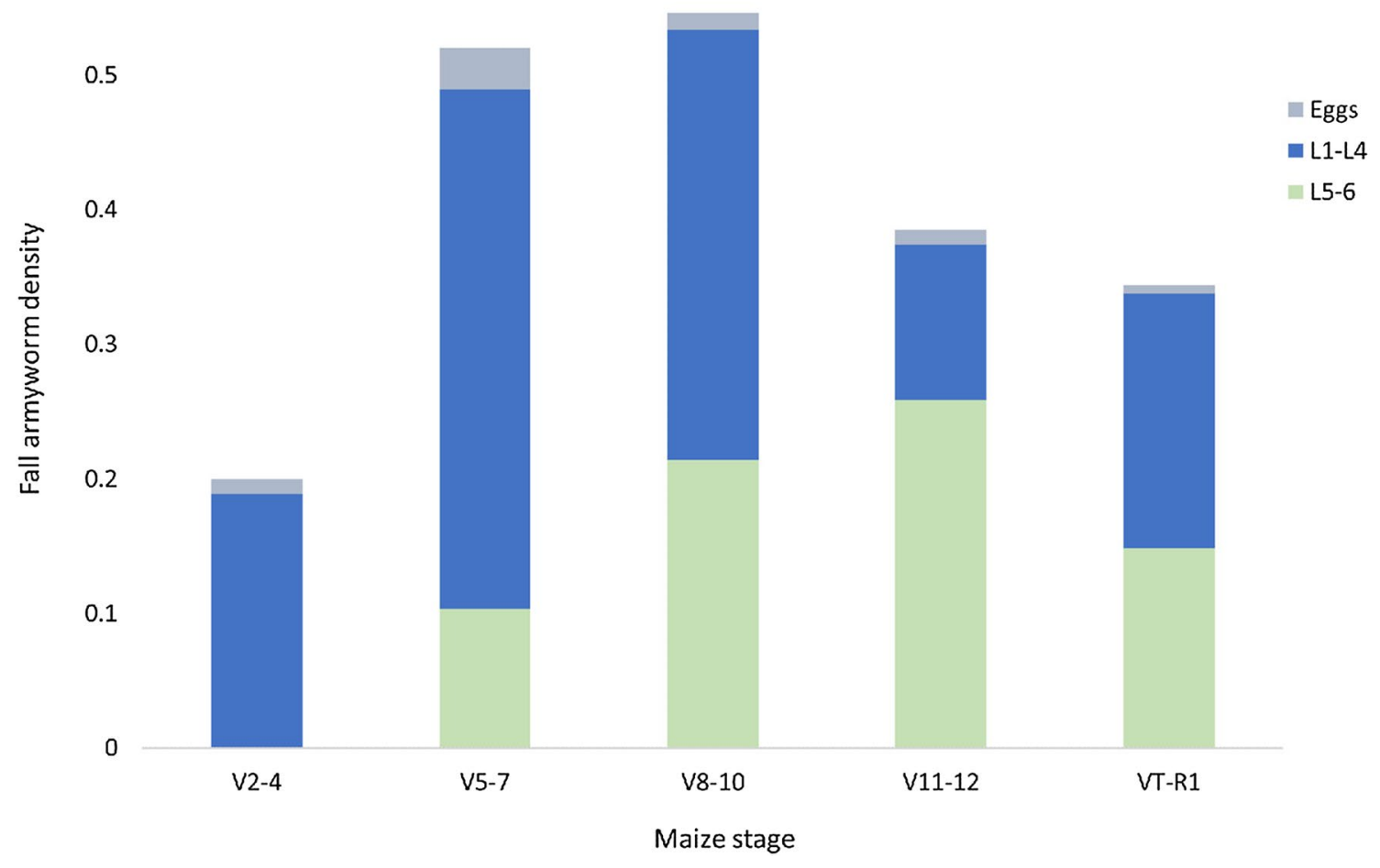

Fig. 6 FAW density for eggs, early and late larval stage in relation to growth stages. FAW density is the total number of FAW present per number of plants checked at each stage of maize development

Publisher's Note Springer Nature remains neutral with regard to jurisdictional claims in published maps and institutional affiliations. 